\title{
Recent developments in analytical techniques for characterization of ultra pure materials-An overview
}

\author{
V BALARAM \\ National Geophysical Research Institute, Hyderabad 500 007, India
}

\begin{abstract}
With continual decrease of geometries used in modern IC devices, the trace metal impurities of process materials and chemicals used in their manufacture are moving to increasingly lower levels, i.e. ng/g and pg/g levels. An attempt is made to give a brief overview of the use of different analytical techniques in the analysis of trace metal impurities in ultrapure materials, such as, high-purity tellurium (7N), high purity quartz, high-purity copper $(6 \mathrm{~N})$, and high purity water and mineral acids. In recent times mass spectrometric techniques such as ICP-MS, GD-MS and HR-ICP-MS with their characteristic high sensitivity and less interference effects were proved to be extremely useful in this field. A few examples of such application studies using these techniques are outlined. The usefulness of other analytical techniques such as F-AAS, GF-AAS, XRF, ICP-AES and INAA was also described. Specific advantages of ICP-MS and HR-ICP-MS such as high sensitivity, limited interference effects, element coverage and speed would make them powerful analytical tools for the characterization of ultrapure materials in future.
\end{abstract}

Keywords. High purity tellurium (7N); ICP-MS; GD-MS; HR-ICP-MS; ultrapure materials; trace metal impurities.

\section{Introduction}

Over the past 10 years, integrated circuit chips (IC), different electronic devices and several other technology products have become smaller and more efficient in terms of performance. The major limiting factor for the size of an integrated circuit chip and its speed is the ultra trace (pg/g level) metal contamination of the silicon used in their manufacturing. For example, high purity quartz is used as a filler material in the encapsulation of discrete and integrated circuit devices. The metal impurities in ultrapure materials lead to higher dark currents that influence the chip's ability to carry currents (Close and Yarwood 1971). Therefore, high purity materials and other chemicals that are used in the IC manufacturing processes must be analysed for ultratrace metal impurities and controlled (Luck 1998). While 10 years ago semiconductor equipment manufacturers institute (SEMI) deemed that $10 \mathrm{ng} / \mathrm{g}$ purity levels were adequate for many chemicals, today $100 \mathrm{pg} / \mathrm{g}$ levels are typical and for some of the more critical materials even $10 \mathrm{pg} / \mathrm{g}$ levels are being proposed. Hence, there is a great need for the analysis of high pure materials for trace element impurities at extremely low concentrations to evaluate the intrinsic properties of different materials required for the semiconductor industry including process chemicals (high-purity water, mineral acids, organic solvents, etc).

balaramv1951@yahoo.co.in

\section{Sample preparation procedures in clean room conditions}

The detection limits for several elements have been quite lowered in recent years because of the introduction of advanced analytical instruments. Pretreatment of samples is required by using different acids and other reagents before injection into the analytical instruments. It is absolutely necessary to process the samples with appropriately pure reagents in addition to clean environment, in order to prevent contamination of the samples. Acids such as $\mathrm{H}_{2} \mathrm{SO}_{4}$ and $\mathrm{H}_{2} \mathrm{PO}_{4}$ introduce new problems in the sample decomposition and analysis using analytical techniques like inductively coupled plasma mass spectrometry (ICPMS). These acids do not completely decompose in the plasma and adhere to the interface components and ion lenses resulting in signal instability (Van et al 2001). Additionally, their higher impurity levels, when compared to nitric and hydrochloric acids, result in an increase in analytical blank. If the magnitude and uncertainty of the analytical blank is not controlled, the analysis of $\mathrm{pg} / \mathrm{g}$ level impurities is impossible. Hence, the quality of acids and other chemical reagents is of paramount importance when dealing with the analysis of high purity materials and working at $\mathrm{ng} / \mathrm{g}$ and sub-ng/g concentration levels. Closed vessel microwave sample preparation has been acknowledged as one of the best solutions for clean chemistry applications (Balaram et al 2000). The use of closed-vessel microwave sample preparation techniques minimize the analytical blank by minimizing the amounts of reagents used and also by controlling the decomposition 
environment. Such studies also require rigorous control over the laboratory environment and improved methods of characterizing trace element impurities.

The determination of impurities in high-purity materials must be carried out under special clean working conditions. Factors include the cleanliness of the laboratory, specific method of sample preparation for analysis, selection of vessels, and purification and storage of reagents (Van et al 2001). The sample preparation facility and the analytical instrument must be housed in a class-1000 clean room. All sample preparations and other manipulations must exclusively be processed in a class-10 clean hood. Closed-vessel microwave sample preparation minimizes airborne contamination during sample decomposition and evaporation. Reagent impurities are further minimized by the use of sub-boil distilled water (Balaram et al 2000).

\section{Analysis by ICP-MS, GD-MS and HR-ICP-MS}

Traditionally, ICP-MS has been the technique of choice for ultra low trace element determinations in high purity chemicals because of its very high sensitivity since almost two decades (Van et al 2001; Balaram and Gnaneswara Rao 2003). The problem of spectral interferences has always been considered as severe impediment of this otherwise a powerful technique. This is because of the limited resolution (unit resolution) offered by the quadrupole mass filters that are used in conventional ICP-MS instruments. New approaches such as collision/reaction cell, and cool plasma technologies are being developed for improving the detection limits by eliminating many spectral interferences. Collision/reaction cell approaches utilize ion-molecule chemistry to eliminate many argonand solvent-based interferences (Denoyer et al 1999). Under cool plasma conditions (500-800 W of RF power and a $1.5-1.81 / \mathrm{min}$ nebulizer gas flow), ionization reactions in the plasma are changed in such a manner that many of the typical polyatomic interferences are reduced. The result is that detection limits are improved for a number of critical semiconductor elements, including Fe, K and $\mathrm{Ca}$. However, because the cool plasma contains much less energy than normal high-temperature plasma, the instrument's sensitivity for the majority of elements can be severely affected by sample matrix (Woolenweber et al 1999). The most straightforward approach to overcome limitations from spectral interferences is the application of high resolution inductively coupled plasma mass spectrometry (HR-ICP-MS). Ultra trace element analysis of copper 6N material (purity, 99.9999\%) was carried out using HR-ICP-MS by Patterg and Matschat (1999). Samples were introduced into the instrument by three different sample introduction systems, viz. continuous nebulization (CN), flow injection analysis (FIA) and laser ablation (LA). The effectiveness of the method was checked by the analysis of high-purity copper reference materials (BCR CuO74). This method also offered the possibility to check for potential losses of analytes occurring during the wet chemical operations. Table 1 presents a comparison of certified values with those obtained by HR-ICP-MS (Patterg and Matschat 1999). In order to analyse solid samples by mass spectrometric methods

Table 1. Comparison of certified values and values obtained by HR-ICP-MS using continuous nebulization (Patterg and Matschat 1999).

\begin{tabular}{|c|c|c|c|}
\hline Element & $\begin{array}{c}\text { BCR074 } \\
\text { Certified value } \pm \text { uncertainty } \\
(95 \% \text { c.i. })(\mu \mathrm{g} / \mathrm{g})\end{array}$ & Measured isotope & $\begin{array}{c}\text { HR-ICP-MS } \\
\text { average of } n \text { values } \pm \text { uncertainty } \\
(95 \% \text { c.i. })(\mu \mathrm{g} / \mathrm{g})\end{array}$ \\
\hline $\mathrm{Ag}$ & $12 \cdot 80 \pm 0 \cdot 70$ & $\begin{array}{l}{ }^{107} \mathrm{Ag} \\
{ }^{109} \mathrm{Ag}\end{array}$ & $\begin{array}{l}12 \cdot 85 \pm 0 \cdot 30 \\
12 \cdot 87 \pm 0 \cdot 30\end{array}$ \\
\hline As & $0 \cdot 78 \pm 0 \cdot 14$ & ${ }^{75}$ As & $0.78 \pm 0.04$ \\
\hline $\mathrm{Bi}$ & $0 \cdot 10 \pm 0 \cdot 03$ & ${ }^{209} \mathrm{Bi}$ & $0 \cdot 098 \pm 0 \cdot 004$ \\
\hline $\mathrm{Cr}$ & $<0 \cdot 10$ & ${ }^{52} \mathrm{Cr}$ & $0 \cdot 05 \pm 0 \cdot 016$ \\
\hline $\mathrm{Fe}$ & $1 \cdot 14 \pm 0 \cdot 06$ & ${ }^{56} \mathrm{Fe}$ & $1 \cdot 14 \pm 0 \cdot 11$ \\
\hline $\mathrm{Ni}$ & $1 \cdot 04 \pm 0 \cdot 11$ & $\begin{array}{l}{ }^{58} \mathrm{Ni} \\
{ }^{60} \mathrm{Ni}\end{array}$ & $\begin{array}{l}0.98 \pm 0 \cdot 04 \\
1 \cdot 14 \pm 0 \cdot 04\end{array}$ \\
\hline $\mathrm{Pb}$ & $0 \cdot 97 \pm 0 \cdot 05$ & $\begin{array}{l}{ }^{207} \mathrm{~Pb} \\
{ }^{208} \mathrm{~Pb}\end{array}$ & $\begin{array}{l}0 \cdot 96 \pm 0 \cdot 024 \\
0 \cdot 96 \pm 0 \cdot 021\end{array}$ \\
\hline $\mathrm{Sb}$ & $058 \pm 0 \cdot 03$ & $\begin{array}{l}{ }^{121} \mathrm{Sb} \\
{ }^{123} \mathrm{Sb}\end{array}$ & $\begin{array}{l}0 \cdot 60 \pm 0 \cdot 020 \\
0 \cdot 60 \pm 0 \cdot 018\end{array}$ \\
\hline $\mathrm{Sn}$ & $<0.07$ & $\begin{array}{l}{ }^{118} \mathrm{Sn} \\
{ }^{120} \mathrm{Sn}\end{array}$ & $\begin{array}{l}0.033 \pm 0.007 \\
0.036 \pm 0.012\end{array}$ \\
\hline
\end{tabular}

Number of different dissolutions $=5$; Number of parallel determinations $=3-7$; c.i. $=$ confidence interval; No. of determinations $=26-29$. 
without dissolution steps, a radio frequency glow discharge ion source was coupled to either a quadrupole mass spectrometer or to a double focusing magnetic sector mass spectrometer (GD-MS). This approach minimizes contamination problems associated with sample dissolution. The results of the analysis of high-purity tellurium by ICP-MS compare well with those obtained by GDMS (table 2), proving that these two are ideal techniques for the analysis of high pure materials. In the case of ICP-MS analysis, replicate samples were dissolved using sub-boil nitric acid. Sample dissolution, analysis and other aspects are discussed elsewhere (Balaram et al 2005). Karunasagar et al (2000) used ICP-MS for the determination of trace amounts of boron in high-purity quartz.

A method was designed for the precise estimation of a few trace and ultratrace elements in high purity sub-boil

Table 2. Trace element concentrations (ng/g) in high pure tellurium by ICP-MS and GD-MS in comparison with purity requirements.

\begin{tabular}{lccccccc}
\hline Element & ICP-MS* $^{*}$ & GD-MS $^{@}$ & $7 \mathrm{~N}$ & Element & ICP-MS* $^{*}$ & GD-MS $^{\circledR}$ & $7 \mathrm{~N}$ \\
\hline $\mathrm{Li}$ & $<1$ & $<3$ & $<5$ & $\mathrm{Ni}$ & $<10$ & $<2$ & $<2$ \\
$\mathrm{Be}$ & $<1$ & $<4$ & $<2$ & $\mathrm{Cu}$ & $<5$ & $<5$ & $<2$ \\
$\mathrm{~B}$ & $<10$ & $<4$ & $<5$ & $\mathrm{Zn}$ & $<10$ & $<9$ & $<8$ \\
$\mathrm{~F}$ & - & $<50$ & $<10$ & $\mathrm{As}$ & $<10$ & $<3$ & $<1$ \\
$\mathrm{Na}$ & $<10$ & $<3$ & 15 & $\mathrm{Rb}$ & $<10$ & $<2$ & $<1$ \\
$\mathrm{Al}$ & $<10$ & $<2$ & 20 & $\mathrm{Ag}$ & $<10$ & $<3$ & $<1$ \\
$\mathrm{P}$ & $<1$ & $<3$ & 2 & $\mathrm{Ba}$ & $<10$ & $<2$ & $<7$ \\
$\mathrm{~K}$ & $<10$ & $<45$ & $<30$ & $\mathrm{Mo}$ & $<10$ & $<1$ & $<0 \cdot 5$ \\
$\mathrm{Ca}$ & $<10$ & $<50$ & $<30$ & $\mathrm{Sr}$ & $<10$ & $<0 \cdot 7$ & $<1$ \\
$\mathrm{Cr}$ & $<5$ & $<4$ & $<1$ & $\mathrm{~Pb}$ & $<10$ & $<2$ & $<1$ \\
\hline
\end{tabular}

-, not determined; 7N, purity requirements; *, at NGRI, Hyderabad (ELAN DRC II); ${ }^{\circledR}$ at Institute for National Measurement Standards, National Research Council, Canada.

Table 3. Concentrations of some trace elements in sub-boil distilled water, sub-boil distilled hydrochloric and nitric acids (Balaram et al 2000).

\begin{tabular}{|c|c|c|c|c|c|}
\hline \multirow[b]{2}{*}{ Element } & \multirow[b]{2}{*}{$\begin{array}{l}\text { Sub-boil distilled } \\
\text { water }(\mathrm{ng} / \mathrm{g}) \\
\text { NGRI }^{1}\end{array}$} & \multicolumn{2}{|c|}{$\begin{array}{l}\text { Sub-boil distilled } \\
\text { hydrochloric acid }\end{array}$} & \multicolumn{2}{|c|}{$\begin{array}{l}\text { Sub-boil distilled } \\
\text { nitric acid (ng/g) }\end{array}$} \\
\hline & & $\begin{array}{r}\mathrm{NGRI}^{1} \\
(\mathrm{ng} / \mathrm{g})\end{array}$ & $\begin{array}{c}\mathrm{SEMI}^{2} \\
(\mu \mathrm{g} / \mathrm{g})\end{array}$ & $\begin{array}{c}\mathrm{NGRI}^{1} \\
(\mathrm{ng} / \mathrm{g})\end{array}$ & $\begin{array}{l}\text { SEMI }^{2} \\
(\mu \mathrm{g} / \mathrm{g})\end{array}$ \\
\hline $\mathrm{Be}$ & $<0.01$ & $<0.01$ & - & $<0.01$ & - \\
\hline B & $2 \cdot 88$ & $2 \cdot 65$ & $0 \cdot 1$ & $10 \cdot 68$ & 1 \\
\hline $\mathrm{V}$ & - & - & - & 4.96 & - \\
\hline $\mathrm{Cr}$ & $0 \cdot 10$ & $8 \cdot 30$ & 1 & 54.55 & $0 \cdot 1$ \\
\hline $\mathrm{Mn}$ & $<0.01$ & $<0.01$ & 1 & $27 \cdot 22$ & 0.5 \\
\hline $\mathrm{Fe}$ & $<0.01$ & $<0.01$ & $0 \cdot 2$ & $66 \cdot 01$ & $0 \cdot 2$ \\
\hline Co & $<0.01$ & $<0.01$ & $0 \cdot 1$ & 0.64 & $0 \cdot 5$ \\
\hline $\mathrm{Ni}$ & $<0.02$ & $<0.02$ & $0 \cdot 1$ & $<0.02$ & $0 \cdot 05$ \\
\hline $\mathrm{Cu}$ & $<0.02$ & $13 \cdot 15$ & $0 \cdot 1$ & $75 \cdot 60$ & 0.05 \\
\hline $\mathrm{Zn}$ & $<0.02$ & $<0.02$ & 1 & $0 \cdot 60$ & 1 \\
\hline As & - & $2 \cdot 31^{\#}$ & - & $7 \cdot 38$ & - \\
\hline $\mathrm{Se}$ & $0 \cdot 25$ & $<0.01$ & - & $6 \cdot 61$ & - \\
\hline $\mathrm{Rb}$ & 0.01 & $<0.01$ & - & 0.05 & - \\
\hline $\mathrm{Sr}$ & $<0.01$ & $<0.02$ & 1 & $<0.01$ & 1 \\
\hline Mo & $0 \cdot 56$ & $<0.01$ & - & $8 \cdot 27$ & - \\
\hline $\mathrm{Ag}$ & 0.49 & 0.88 & $0 \cdot 1$ & $0 \cdot 18$ & $0 \cdot 5$ \\
\hline $\mathrm{Cd}$ & $<0.01$ & $<0.01$ & 1 & $0 \cdot 11$ & $0 \cdot 5$ \\
\hline $\mathrm{Sb}$ & $<0.01$ & $<0.01$ & - & $0 \cdot 11$ & - \\
\hline $\mathrm{Ba}$ & $<0.01$ & 0.07 & 1 & $<0.01$ & 1 \\
\hline $\mathrm{Tl}$ & 0.04 & 0.04 & - & 0.03 & - \\
\hline $\mathrm{Pb}$ & 0.04 & 0.05 & - & 0.55 & - \\
\hline $\mathrm{Bi}$ & $<0.01$ & $0 \cdot 13$ & - & $1 \cdot 39$ & - \\
\hline
\end{tabular}

1. PlasmaQuad PQ1; 2. SEMI = Semiconductor Equipment Manufacturer's Institute; specification for reagents, CI STD 21-85; measurement precision, < 5\% RSD in both cases.

\# as was determined by GF-AAS with Zeeman background correction facility; -, not available. 
distilled water and hydrochloric and nitric acids using ICP-MS. The trace element concentrations of majority of the elements analysed in sub-boil distilled water were found to be below detection limits of the technique. A comparison of the trace element impurity levels obtained in hydrochloric and nitric acids with the maximum allowable impurity levels for high purity reagents documented by SEMI (table 3) suggests that these purity levels of sub-boil hydrochloric acid and nitric acids used in those studies comply with the specifications given for high pure reagents (Balaram et al 2000).

\section{Other analytical techniques}

Instrumental neutron activation analysis (INAA) is also an established technique for the analysis of ultrapure materials (Baumann and Pavel 1989). But requirements, such as, sample irradiation in a reactor and longer cooling times make this technique unsuitable for such industrial applications. Some of the elements like $\mathrm{Cl}$ and $\mathrm{S}$ can be conveniently determined by X-ray fluorescence spectrometry (XRF), as for many of the metals, the detection limits offered by XRF are not adequate. However, XRF was successfully utilized for the determination of impurities in surface layers of semiconductor materials (Fan et al 1993). Inductively coupled plasma atomic emission spectrometry (ICP-AES) offers ng/g and sub-ng/g detection limits for several elements in different matrices. This is also a potential analytical tool for the analysis of ultrapure materials. Flame atomic absorption spectrometry (F-AAS) technique cannot detect and determine metals at $\mathrm{ng} / \mathrm{g}$ levels in many cases. Though graphite furnace atomic absorption spectrometry (GF-AAS) possesses the required sensitivity, it is a slow technique and the analytical procedures in general are very cumbersome. Moreover, both F-AAS and GF-AAS are not multi-element techniques and cannot meet the throughput requirements.

\section{Conclusions}

To keep pace with the increasingly stringent requirements of the analysis of ultra pure materials, analytical instrumentation must undergo continual improvement. The detection limits offered by different mass spectro- metric techniques, such as ICP-MS, GD-MS and HRICP-MS are significantly lower than those normally offered by optical and nuclear techniques, such as ICPAES, XRF and INAA. The high sensitivity and versatility of ICP-MS technique makes it uniquely suited to the trace analysis of ultra pure materials. Most of the elements can be estimated with required accuracies at concentration levels $<0.01 \mathrm{ng} / \mathrm{g}$ in solution with current generation ICP-MS instruments. The results presented here demonstrate that GD-MS is also a potential analytical technique for the analysis of ultra pure materials. Currently ICP-MS and HR-ICP-MS are very extensively being used for the determination of ultratrace impurities in high pure materials especially in the areas of semiconductor research.

\section{Acknowledgements}

The author is thankful to Dr N R Munirathnam, C-MET, Hyderabad for GD-MS results. Dr N P Rajendra Prasad, NGRI, Hyderabad, is also thanked for his valuable comments on the earlier version of the manuscript.

\section{References}

Balaram V and Gnaneswara Rao T 2003 Atomic Spectrosc. 24 206

Balaram V et al 2000 Indian J. Chem. A39 567

Balaram V, Reddy M R P, Munirathnam N R and Anjaiah K V 2005 Atomic Spectrosc. (communicated)

Baumann H and Pavel J 1989 Microchim. Acta [Wien] III 413

Close K J and Yarwood J 1971 An introduction to semiconductors (London: Heinemann)

Denoyer E, Tanner S and Voellkopf U 1999 Atomic Spectrosc. 142

Fan Q M, Liu Y W, Li D L and Wei C L 1993 Fresenius J. Anal. Chem. 345518

Karunasagar D, Das K, Chandrasekharan K and Arunachalam J 2000 Atomic Spectrosc. 21216

Luck J H 1998 Spectroscopy 31

Patterg S and Matschat R 1999 Fresenius J. Anal. Chem. 34410

Van Y, Kingston H M, Richter R C and Pirola C 2001 Anal. Chem. 731106

Woolenweber D, StraBurg S and Wunsch G 1999 Fresenius J. Anal. Chem. 364333 